\title{
F-3 - Biochemistry in poetry: A teaching experience using collaborative learning methodology to learning Biochemistry at the Medical School
}

\author{
Silvia Regina Tozato Prado ${ }^{1}$ \\ ${ }^{1}$ Pontifical Catholic University of Paraná, Medicine School (Paraná, Brazil)
}

\begin{abstract}
INTRODUCTION: Generally, the learning of Biochemistry is too hard for college student. Biochemistry required the abstract thinking to understanding the molecular level the metabolism of living and it demands a great capacity for imagination that the cell habitat is. OBJECTIVES: The Biochemical learning experience carried out connecting Biochemistry and Literature to provide a collaborative learning method. MATERIALS AND METHODS: The students of the School of Medicine, PUC-PR, that course the disciplines of Medical Biochemistry II, was organized in 33 groups each with 3-4 students and they had to write a poem with a specific theme related to Biochemistry, that was selected: lipid metabolism, metabolic integration, dyslipidemia and atherogenesis, pathophysiology of diabetes mellitus disease, diabetes mellitus complications, metabolic syndrome and obesity. The groups had to: write the poem and presents it to class orally and to expose a poem's banner at the wall in the University for about one month. Instead that they had to fill an evaluation sheet and finally, all groups together had to organized a printed book titled "Biochemistry in poetry". DISCUSSION AND RESULTS: Many groups pointed out to elaborate own texts and used academic vocabulary about Biochemistry theme were too hard and hard, respectively. $73 \%$ of the groups said the activity help them to learning a new thing and $79 \%$ agree that the activity help them to learning the specific Biochemistry topic. Other points to evaluated for groups. CONCLUSION: This demonstrates the need of activities that exercise writing on biochemical topics collaborating with the scientific growth of the college students. This activity promoted major learning about specific Biochemistry theme and the development to others desired skills in the profile of that the course proposes, like to collaborative work and to present your work in public. Instead that, to use a different learning methodology helps students develop the abstract thinking necessary for Biochemistry learning.
\end{abstract}

Keywords: Biochemistry learning; collaborative methodology; biochemical poem. 